\title{
The League of Nations and the Fight against Leprosy.
}

\section{ETIENNE BURNET.}

TN 1925 the Health Committee of the League of Nations decided to institute an enquiry into certain statistical and - epidemiological aspects of leprosy; as a result of this enquiry, the Health Committee appointed a Leprosy Commission, on which the following nations are represented : Germany, Brazil, United States of America, Great Britain, British India, Japan, Union of South Africa.

In order to understand its work it should be explained that the Leprosy Commission of the League of Nations is different from other institutions devoted to leprosy. It is not an international study society, such as has recently been proposed should be founded. It is not a society for scientific medical research and social action, like the British Empire Leprosy Relief Association or the Leonard Wood Memorial for the Eradication of Leprosy. It is not a mission inspired by the religious spirit, like the Mission to Lepers. It is neither a scientific society nor a health authority. These various institutions are primarily societies devoted to leprosy. The essential character of the Commission, as of the Health Committee from which it springs, is that it is international and universal. It has for its aim the bringing together of the forces existing in the world for a useful work and to arrive at an agreement, with a view to action, on disputed questions. Those who criticise it because it is not an assembly of technical specialists do not understand it. If it contains both specialists and at least an equal number of responsible heads of great public health authorities, it is because these men are best qualified to put into practice the conclusions of the Commission. The Leprosy Commission, like all the Commissions of the League of Nations, always invites the collaboration of specialists, either in sub-commissions or individually, in as great a number and for as long a time as is necessary. Its method of work consists in bringing together the men of different nations, in facilitating the exchange of ideas, in bringing the questions to a head in conferences of experts, and in taking the responsibility for conclusions that are recommended to governments.

The first concern of the Leprosy Commission was to obtain knowledge of the situation of leprosy in the world, not merely from the bibliography, but by direct observation; it instructed its secretary to visit not only institutions, 
leprosaria, hospitals and dispensaries, but doctors, laboratory workers, hygienists and administrators in countries where leprosy was prevalent. This was done in order to be able to work out a programme that would be generally acceptable.

Nobody nowadays doubts that the campaign against leprosy, like so many other sanitary and economic activities, must be organised on an international scale. The trade in raw materials between the temperate zone and the tropics has multiplied the opportunities of contagion between the inhabitants of countries exempt from leprosy and those of infected regions. Owing to the dispersion of leprosy in the five parts of the world and especially in countries where the conditions of life are still primitive, leprologists are widely separated, and many of them are isolated and "lost" as are prospectors in new countries. There is no uniformity either in the scientific language or in the technique of treatment, where methodical comparisons would be so useful. Leprologists are not agreed either on a classification of the forms of leprosy or on the definitions of the symptoms and lesions, and agreement is indispensable if it is desired to measure the still disputed results of treatment. On the other hand, governments, before committing themselves to the considerable expense that the fight against leprosy requires, expect that the most efficacious system should be recommended by a technical authority of a universal nature such as can be possessed only by a conf erence of specialists where all opinions are represented. It is no exaggeration to say that for ten years doctors, health authorities, scientific and medical associations, missions and governments have all been looking to the League of Nations to give a general impulse and direction to the new crusade against leprosy.

This appeal to the League of Nations was expressed as early as 1923 by the Strassburg Conference, then by a considerable number of interested persons, and finally quite recently by the Wood Memorial Conference on Leprosy at Manila.

In the course of his enquiry, ${ }^{*}$ the Secretary of the Leprosy Commission found leprologists very divided upon the two chief questions, segregation and treatment. Some were convinced that treatment by chaulmoogra oil and its derivatives would cure all cases of leprosy if they were taken early enough. According to others, there are no proofs that

* The report was published in May, 1930. Report on the Study Tour of the Secretary of the Leprosy Commission in Europe, South America and the Far East, January, 1929, to June, 1930. Geneva, 1930. (League of Nations Health Organisation, Official No. C.H.887.) 
general and dietetic treatment plus chaulmoogra derivatives give any better results than general and dietetic treatment alone ; the comparisons of two equivalent groups of patients, the one receiving and the other not receiving chaulmoogra treatment, is a fundamental experiment that has never been made. On the question of segregation, some believe that the internment of cases in leprosaria remains the corner stone of prophylaxis; others go so far as to say that segregation does more harm than good, because it frightens the sufferers, who hide themselves, escape early treatment and allow their contagious leprosy to develop to the stage when it becomes incurable.

In British India, under the direction of the British Empire Leprosy Relief Association the Propaganda Treatment Survey (P.T.S.) system was put into practice. This is an admirable development of what French Colonial doctors used to call as early as 1917 " the free treatment " of leprosy. In Japan faith is still pinned to segregation.

In theory it would seem very difficult to rally the two parties to a common doctrine, but already the evidence of well proved facts and practical needs were imposing complex solutions. It was reported that the prevention of leprosy is not a problem capable of a simple solution and that the means to be employed vary of necessity with the geographical, economic, administrative, financial and other conditions of the leprous countries. The relative efficacy of treatment at least, could not be denied. The old compulsory segregation, in its mediæval form, was rejected in most countries for both scientific and humanitarian reasons; the isolation of contagious cases, however, was not relinquished and asylums for indigent cases and for incurables will always be necessary. India retained leprosaria under the P.T.S. system and Japan reported that only the contagious ones were confined in the leprosaria. The practical system in the Philippines evolved under the influence of the P.T.S. system influences in its turn many other countries. The necessity for as early treatment as possible was recognised. The two parties (adherents and adversaries of segregation; believers and sceptics as regards treatment) have been obliged in practice to make concessions which give grounds for the belief that they will come to some agreement on a programme of prophylaxis. The report of the Secretary of the Commission infers the possibility of international agreement and action.

At the same time as this enquiry was paving the way for the work of the Leprosy Commission, a society founded in 1928 in the United States, the Leonard Wood Memorial 
for the Eradication of Leprosy, was organising a conference of leprosy specialists. It appeared at first sight useful to join the two conferences, but then it was deemed preferable to let each retain its independent character. The League of Nations Co:nmission held its conference in December, 1930, at Bangkok, at the same time as the Eighth Congress of the Far Eastern Association of Tropical Medicine. The Leonard Wood Memorial Conference was held in January, 1931, at Manila. The members of the Leprosy Commission of the League of Nations having been invited, in a personal capacity, to sit as members of the Leonard Wood Memorial Conference at Manila, there was collaboration and continuity between the two conferences.

Members of the Bangkok Conference : President, Dr. Bernhard Nocht, Director of the Institut für Schiffs-und-Tropenkrankheiten, Hamburg; Members, Professor Carlos Chagas, Director of the Instituto Oswaldo Cruz, Rio de Janeiro (absent); Surgeon-General H. S. Cumming, Director-General of the United States Public Health Service (absent), represented by Surgeon N. E. Wayson, U.S.P.H.S., Director, United States Leprosy Investigation Station, Honolulu, Hawaii ; Major-General J. D. Graham, I.M.s., Public Health Commissioner with the Government of India, New Delhi; Dr. G. Alexander Mitchell, Director of Public Health, Union of South Africa, Pretoria ; Professor Ernest Muir, M.D., F.R.C.S., Leprosy Research Laboratory, Calcutta School of Tropical Medicine ; Professor Mataro Nagayo, Director of the Government Institute of Infectious Diseases, Imperial University of Tokyo (absent), represented by Dr. Masao Ota, Tohoku Imperial University, Sendai, Japan ; Major-General Sir Leonard Rogers, C.I.E., F.R.S., I.M.S., Hon. Medical Adviser of the British Empire Leprosy Relief Association, London (absent) ; Dr. H. Windsor Wade, Chief Pathologist, Philippine Public Health Service ; Medical Director of the Leonard Wood Memorial for the Eradication of Leprosy, New York; Secretary, Dr. Etienne Burnet, Secretary, Leprosy Commission of the Health Organisation of the League of Nations. The following were also present at the Conference, Dr. C. L. Park, Member of the Health Section of the Secretariat of the League of Nations ; Dr. R. Gautier, Director of Eastern Bureau of the Health Organisation of the League of Nations.

The readers of this REviEw already know the work of the Manila Conference which has so successfully continued the task begun at Bangkok, and prepared for the foundation of an international society of leprosy and of an international review. The Manila Conference insisted upon the international character of the campaign against leprosy. It appealed to the League of Nations for the publication of an international leprosy year-book. We refer readers for further particulars to the Report of the Manila Conference, as the subject of this article is the work of the League of Nations Leprosy Commission.

\section{Principles of the Prophylaxis of Leprosy.}

The chief task of the Commission has been the preparation of a report which proposed, for the first time it seems, 
a doctrine of leprosy prevention, understanding by doctrine a body of rules upon which the leprosy experts and the heads of public health authorities, representing various countries and opinions, have agreed, without claiming to eliminate the peculiarities imposed on each country by its own conditions.

This report* is brief, clear and frank. It is divided into two parts :-

1. The principles of the prophylaxis of leprosy.

2. Technical suggestions.

In the second part, the Commission, knowing that the work would be resumed with its participation at Manila, has defined its position only on technical questions that it had placed on its agends. In the two highly controversial questions of treatment and segregation it has endeavoured to lay down guiding principles which are consonant with the state of our scientific knowledge and the experience of experts in leprosy. It is by reasoned conviction that it upholds segregation (until such time as it can be dispensed with,) while proposing that the old term segregation should be abandoned and the more liberal and medical term isolation should be used instead; it further recommends not only general treatment, but also special treatment by hydnocarpus oil (chaulmoogra) and its derivatives, because the efficacy of these products was recognised.

The Manila Conference has approved in principle the report on prophylaxis of the Leprosy Commission.

\section{Technical Suggestions.}

1. Practical Activity.-The Commission intends to facilitate the relations between leprologists and to realise as far as possible uniformity in study and practice. The year-book suggested by the Manila Conference will be published. For this purpose, it has sent to public health authorities, institutions and missions a questionnaire to which they are asked to give short and precise answers.

According to another resolution of the Bangkok and Manila Conferences, the documents used for clinical and statistical purposes should be standardised; observations, cards, reports, pictures and diagrams. We have asked authorities and institutions to send us their models. We will

* League of Nations. Health Organisation. The Principles of the Prophylaxis of Leprosy. First General Report of the Leprosy Commission. Geneva, April, 1931. (Official No. C.H. 970. Series of the League of Nations Publications III Health. 1931. III. 2.) 
compare them and prepare models which we will have examined by experts and which will be recommended for general use.

While admitting that every case of leprosy must be treated individually, it seems possible to arrive at a certain degree of standardisation in treatment, as regards medicaments on the one hand and methods of application on the other. There must be precision in the definition of remedies, in the technique of extraction, purification and preservation of the hydnocarpus oils, in the determination of their activity indices, and a codification of the preparation of the esters and soaps.

2. Research.-The Manila Conference drew up an extensive programme of clinical and experimental research. The Leprosy Commission, which is neither a scientific society nor a research institute, confines its attention to a small number of questions, the most important and urgent ones for the practice of treatment and prevention ; in recommending this limited programme to the study centres of different leprous countries, it intends to collect and compare the results with the co-operation of international experts.

In the front rank it places the demonstration of the efficacy of treatment by chaulmoogra and its derivatives.

The crucial experiment, consisting of the comparison of two equivalent groups of patients placed under the same conditions, one of which would receive the special chaulmoogra treatment and the other not, raises serious difficulties. It is difficult in one institution to deprive a certain number of lepers of treatment in order that they may serve as controls to the treated patients. Nevertheless, as there may be conditions where this crucial test would be possible, the Commission decided to recommend it.

It then recommends experiments to compare the different forms of special treatment (oils, esters, soaps) and the methods of inoculation (subcutaneous, intramuscular, intradermal).

It hopes that it will be possible at a later date to analyse a sufficiently large number of uniform observations on patients who have received consecutive treatment, and be able to draw from them some indications of the reasons for the success or failure in the different cases.

It recommends research on an early diagnostic reaction, serological or biochemical ; thorough post-mortem examination of persons who have been rendered negative or been cured and who have subsequently died from causes other than leprosy ; full researches on chemotherapy; researches 
into the causes of the decrease of leprosy in certain countries, including the foci still existing in Europe.

3. Establishment of International Study Centres for Leprosy. - There are experts fully prepared for research on leprosy who have only a very small number of patients at their disposal, and there are large groups of patients who are not used for research for want of a sufficient number of doctors or laboratories. The first work of co-ordination consists of bringing the research workers and the cases together. The results obtained at Calcutta, at Culion, at Honolulu and in Japan show the efficacy of a good organisation of study centres.

It is necessary, says the Bangkok Report, that each country where leprosy is endemic should have at least one centre devoted to the theoretical and practical study of the disease. The commission recognises, moreover, the usefulness of international centres which act as clearing stations between the leprous countries, and between the workers of the scientific centres of Europe and North America and the leprous countries. It has decided to establish two international centres, the one at Rio de Janeiro, the other in Japan.

In Brazil, there is abundant material for study already made available by the institutions (administrative centres, leprosaria and dispensaries) of the states of Rio and Säo Paulo. The Brazilian government and a well-known philanthropist, M. Guinle, have given the necessary credits for the organisation of an international centre at Rio under the auspices of the League of Nations.

In Japan the material for study abounds and research on leprosy has at all times been very active; the laboratories of the leprosaria have produced some remarkable works in the whole field, particularly on serological diagnosis and on the culture of the Mycobacterium leprae. The Japanese Government has decided to establish an international centre at Tokyo.

The men invited to work in these new centres will spend a certain time in the institutions at Calcutta, Culion and Honolulu. In 1932, a Japanese leprologist will be appointed to study leprosy in Europe and at Rio, after having passed through Calcutta, Culion and Honolulu, and a leprologist from Europe will study leprosy in the Far East, particularly in Japan.

4. Leprosy and Tuberculosis.-The Bangkok and Manila Conferences did not ignore the analogy that exists between leprosy and tuberculosis, but the leprosy specialists hesitated 
to emphasise this analogy because of certain differences between the two diseases. If it is right to notice the clinical and bacteriological differences, there is nothing but advantage in utilising the resemblances from the point of view of social hygiene and prophylaxis.

The complete system of prophylaxis recommended by the Conferences coincides with the system employed against tuberculosis ; epidemiological control at the base, legislation on compulsory notification, examination of contacts, special hospitals or special services in the hospitals, treatment centres, dispensaries, sanatorium-colonies and refuge-colonies, inspection of schools, social service, re-education for vocational work of improved or cured persons. The classification into open and closed cases is made in both diseases. The regulations which, in England, give to public health authorities the power, by order of a judge, to enforce compulsory hospitalisation of a contagious case of tuberculosis, and which remove such persons from certain occupations (particularly dairy-farming) closely resemble certain regulations with regard to leprosy. Occupational therapy is necessary in leprosy and in tuberculosis. The reality and the duration of cures, and the study of relapses, are two sides of the same critical studies. Against both diseases the organisation of the treatment and the prophylaxis must be regional, administered by the local authorities under the direction of and with grants from the central authority. If hygienists who are not yet familiar with leprosy wish to gain an idea of the system of prophylaxis that they have to apply against this disease, they should remember that methods which are applicable to leprosy are also applicable to tuberculosis.

Such is the international work begun by the Leprosy Commission of the League of Nations to help in the eradication of leprosy from the world. It is a work of encouragement, and rapprochement, exerted upon national and international institutions, utilising the moral authority and means of action that are peculiar to the League of Nations. It is not difficult to see in the activity of the Commission a part of the collaboration that the British peoples bring to bear upon the League of Nations, and the influence of the ideas that inspire the British Empire Leprosy Relief Association and of the examples which it shows in British India and West Africa. 